\title{
RESEARCH
}

Open Access

\section{Mortality calculator as a possible prognostic predictor of overall survival after gastrectomy in elderly patients with gastric cancer}

Hidenori Akaike * D, Yoshihiko Kawaguchi, Suguru Maruyama, Katsutoshi Shoda, Ryo Saito, Shinji Furuya, Naohiro Hosomura, Hidetake Amemiya, Hiromichi Kawaida, Makoto Sudoh, Shingo Inoue, Hiroshi Kohno and Daisuke Ichikawa

\begin{abstract}
s
Background: The number of elderly patients with gastric cancer has been increasing. Most elderly patients have associated reduced physiologic functions that can sometimes become an obstacle to safe surgical treatment. The National Clinical Database Risk Calculator, which based on a large Japanese surgical database, provides predicted mortality and morbidity in each case as the surgical-related risks. The purpose of this study was to investigate the clinical significance of the risk for operative mortality (NRC-mortality), as calculated by the National Clinical Database Risk Calculator, during long-term follow-up after gastrectomy for elderly patients with gastric cancer.

Methods: We enrolled 73 patients aged $\geq 80$ years and underwent gastrectomy at our institution. Their surgical risk was evaluated based on the NRC-mortality. Several clinicopathologic factors, including NRC-mortality, were selected and analyzed as the possible prognostic factors for elderly patients who have undergone gastrectomy for gastric cancer. Statistical analysis was performed using the log-rank test and Cox proportional hazard model.

Results: NRC-mortality ranged from 0.5 to $10.6 \%$, and the median value was $1.7 \%$. Dividing the patients according to mortality, the overall survival was significantly worse in the high mortality group ( $\geq 1.7 \%, n=38$ ) than in the low mortality group $(<1.7 \%, n=35)$, whereas disease-specific survival was not different between the two groups. In the Cox proportional hazard model, multivariate analysis revealed NRC-mortality, performance status, and surgical procedure as the independent prognostic factors for overall survival. For disease-specific survival, the independent prognostic factors were performance status and pathological stage but not NRC-mortality.
\end{abstract}

Conclusion: The NRC-mortality might be clinically useful for predicting both surgical mortality and overall survival after gastrectomy in elderly patients with gastric cancer.

Keywords: Gastric cancer, Elderly, Overall survival, Prognosis, Risk calculator

\footnotetext{
* Correspondence: hakaike@yamanashi.ac.jp

First Department of Surgery, Faculty of Medicine, University of Yamanashi,

1110 Shimokato, Chuo, Yamanashi 4093898, Japan
}

(c) The Author(s). 2020 Open Access This article is licensed under a Creative Commons Attribution 4.0 International License, which permits use, sharing, adaptation, distribution and reproduction in any medium or format, as long as you give appropriate credit to the original author(s) and the source, provide a link to the Creative Commons licence, and indicate if changes were made. The images or other third party material in this article are included in the article's Creative Commons licence, unless indicated otherwise in a credit line to the material. If material is not included in the article's Creative Commons licence and your intended use is not permitted by statutory regulation or exceeds the permitted use, you will need to obtain permission directly from the copyright holder. To view a copy of this licence, visit http://creativecommons.org/licenses/by/4.0/. The Creative Commons Public Domain Dedication waiver (http://creativecommons.org/publicdomain/zero/1.0/) applies to the data made available in this article, unless otherwise stated in a credit line to the data. 


\section{Background}

Japan has been one of the fastest aging societies in the world [1], and surgical strategies for elderly patients have been the emerging issue in geriatric medicine. Gastric cancer is the second most common cancer in Japan, in the background of an aging society, the number of elderly patients with gastric cancer has been increasing [2]. The most effective treatment for gastric cancer is radical gastrectomy with lymph node dissection [3]. However, most elderly patients have associated reduced physiologic functions that can sometimes be an obstacle to safe surgical treatments [4]. In such elderly patients, postoperative complications occur more frequently and may be occasionally fatal $[4,5]$. Therefore, the indications for surgical treatment of elderly patients should be evaluated comprehensively based on a balance of radicality, safety, and appropriateness. Various studies have been performed to predict the prognosis after gastrectomy in elderly patients with gastric cancer. However, almost all studies have reported prognostic factors mainly in terms of avoiding recurrences and reviewed clinicopathologic factors in the same manner as that for nonelderly patients $[6,7]$.

Recently, some large-scale clinical databases have provided surgical data and surgery-related risk calculators for mortality and morbidity $[8,9]$. In Japan, registration in a web-based National Clinical Database (NCD) began in 2011 and has included the clinicopathologic information, surgical results, postoperative complications, and surgery-related deaths of over 4 million cases from more than 4100 facilities over a 3-year period [10]. Information from the NCD has been considered the most reliable baseline data that reflect the common surgical practices in Japan. As a real-time feedback system on the web, the NCD Risk Calculator provides predictive risks of mortality and several main morbidities based on the registered preoperative clinical data of patients who have undergone eight major surgical procedures, including total gastrectomy $[11,12]$ and distal gastrectomy $[13,14]$.

The operative mortality calculated by the NCD Risk Calculator (NRC-mortality) has been widely used to assess the safety of surgical treatment in clinical practice. In this study, we aimed to investigate the clinical significance of NRC-mortality during the long-term follow-up after gastrectomy for elderly patients with gastric cancer, based on the assumption that the NRC-mortality would reflect the general condition of each patient.

\section{Methods}

\section{Patients}

Ninety-eight patients aged 80 or more years and who have undergone gastrectomy for gastric cancer at the University of Yamanashi Hospital between 2001 and 2014 were included. This study excluded 7 patients with remnant gastric cancer, 14 patients with $\mathrm{R} 1$ or R2 resection, and 4 patients who were lost to follow-up. Finally, 73 elderly patients were enrolled in this study, which reviewed the clinicopathologic data from the medical records. Surgical risk was evaluated based on the NRCmortality.

Several clinicopathologic factors were selected and analyzed as predictive prognostic factors among elderly patients with gastric cancer after gastrectomy. These included patient-related factors, such as sex, performance status of Eastern Cooperative Oncology Group (ECOG-PS), Glasgow prognostic score (GPS), Onodera's prognostic nutritional index (PNI) [15], and NRC-mortality. All these factors were calculated at the time of admission for surgery. The tumorrelated factors were pathologic stage of gastric cancer (pStage), and treatment-related factors were surgical procedure, lymph node dissection, operative time, blood loss, postoperative complications defined as Clavien-Dindo grade 2 or more and adjuvant chemotherapy.

The clinicopathologic findings were classified based on the 8th edition Union for International Cancer Control TNM classification [16]. Lymph node dissection was performed in principle, according to the gastric cancer treatment guidelines of the Japanese Gastric Cancer Association [17]. Each factor was assessed as an indicator of patient prognosis, in terms of overall survival (OS) and disease-specific survival (DSS) from the date of surgery. The observation period for this study was up to 5 years after surgery.

All procedures carried out in this study were in accordance with the ethical standards of the responsible institutional and national committees on human experimentation and with the Helsinki Declaration of 1964 and its later amendments or equivalents. This study was approved by the University of Yamanashi Faculty of Medicine Ethics Committee.

\section{NCD Risk Calculator}

The NCD Risk Calculator is one of the functions of the NCD feedback. A risk model was constructed based on the NCD registration data to calculate predictive values, such as mortality and complication rate, in patients undergoing surgery. In other words, after input of the preoperative risk of each case, the outcome was calculated from the case data registered nationwide and feedback was immediately given to each department.

Using the NCD Risk Calculator is very easy. First, access the NCD Risk Calculator on the web and select the surgical procedure to perform. Next, input and submit age, sex, physical findings, comorbidities, living history, medical history, preoperative blood test values, American Society of Anesthesiologists Physical Status Classification, etc. All the items required for this entry are confirmed before surgery. The outcome of each surgery is calculated 
only in two steps as shown in Fig. 1. The outcome items calculated using the NCD Risk Calculator vary slightly for different surgical procedures. Common outcomes of distal gastrectomy and total gastrectomy include mortality within 30 days after surgery (30-day mortality), 30-day mortality or in-hospital mortality (up to 90 days after surgery) (operative mortality), anastomotic leakage, postoperative pneumonia, and renal dysfunction are calculated [11-14]. However, the NCD Risk Calculator is only available to NCD registered members.

\section{Statistical analysis}

All statistical analyses were carried out using the statistical computing software $\mathrm{R}$ version 3.4.4 (R Foundation for Statistical Computing, Vienna, Austria). Survival curves were estimated using the Kaplan-Meier method and statistical analysis was performed using the log-rank test. The Cox proportional hazard model was used to calculate hazard ratios for OS and DSS. Statistical significance was set at $p<0.05$.

\section{Results}

The patient's characteristics are shown in Table 1. Total gastrectomy was performed on 28 patients and distal gastrectomy was performed on 45 patients. Laparoscopic surgery was performed on 11 patients. Postoperative complications developed in 22 patients; the most common was pneumonia in 5 patients, followed by anastomotic leakage in 4 patients. Recurrence was observed in
15 patients, 7 of whom developed liver metastasis. During the follow-up period of 5 years after surgery, 33 patients died of gastric cancer $(n=13)$ and other diseases $(n=20)$. There were two surgery-related deaths within 90 days after surgery.

NRC-mortality ranged $0.5-10.6 \%$ (median, $1.7 \%$ ). The patients were divided into two groups according to the median value, high mortality group (NRC-mortality, $\geq$ $1.7 \%$ ) and low mortality group (NRC-mortality, $<1.7 \%$ ), to investigate the postoperative prognostic usefulness of the NRC-mortality. Thirty-eight patients were classified as the high mortality group, whereas 35 patients were classified as the low mortality group. Figure 2 shows the survival curves of each group. Compared with the low mortality group, high mortality group had significantly worse prognosis in terms of OS, but there was no difference in DSS. No significant difference was noted in the rates of patients with pStage II or III except for T1 who received adjuvant chemotherapy between the high- and low-mortality groups. In addition, no difference was also observed between the two groups in the rates of patients who received chemotherapy after recurrence.

In the Cox proportional hazard model, univariate analysis showed that NRC-mortality, ECOG-PS, PNI, surgical procedure, and postoperative complications were significantly correlated with OS, however, sex, GPS, pStage, lymphadenectomy, operative time, blood loss, and adjuvant chemotherapy were not. Multivariate analysis showed that ECOG-PS, NRC-mortality, and surgical

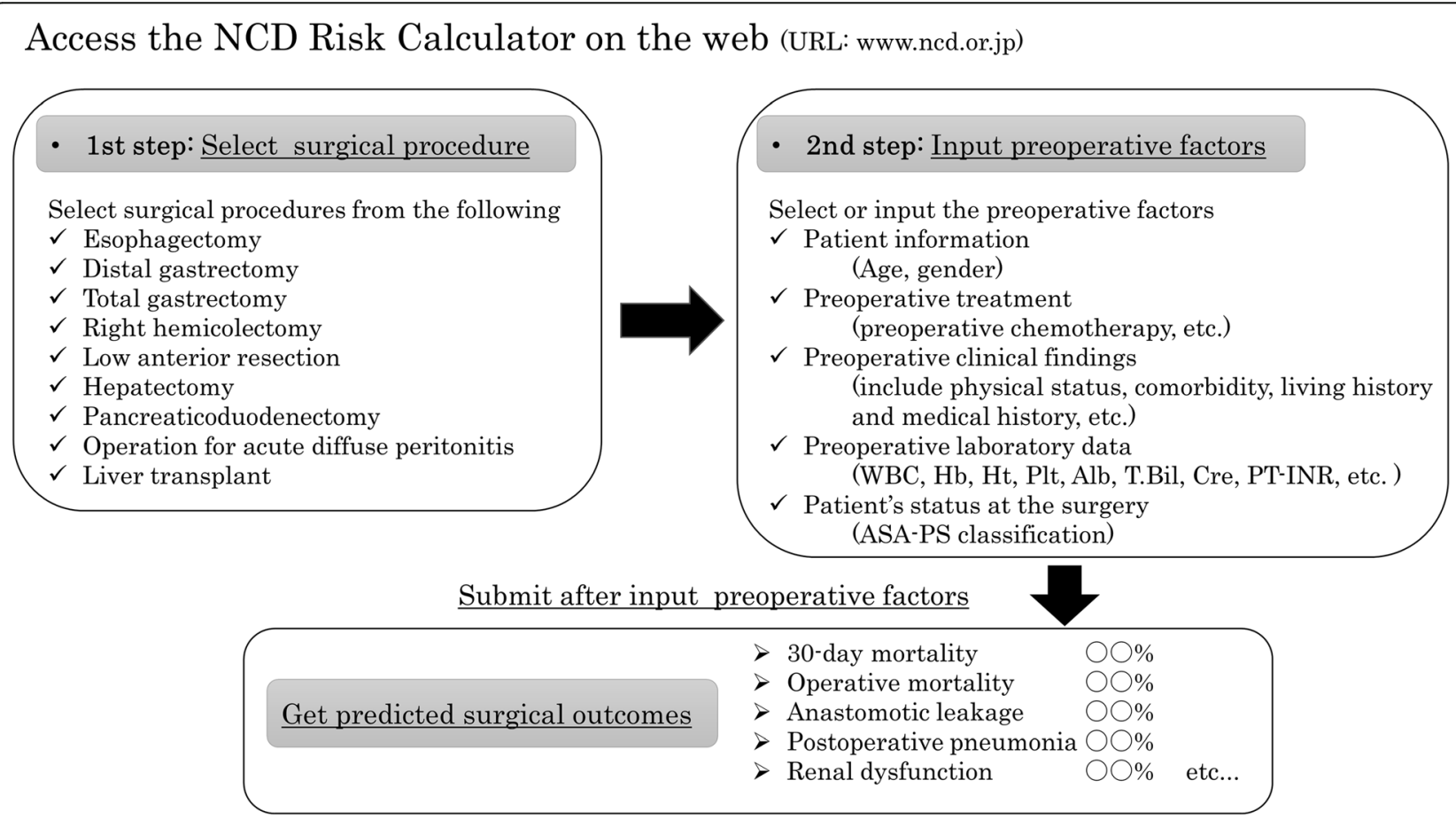

Fig. 1 Outline of the use of the National Clinical Database risk calculator. ASA-PS: American Society of Anesthesiologists Physical Status 
Table 1 Patients characteristics

\begin{tabular}{ll}
\hline & $\boldsymbol{n}=\mathbf{7 3}$ \\
\hline Age (years) & $82[80-95]$ \\
Sex (male/female) & $45 / 28$ \\
ECOG-PS (0/1/2/3) & $16 / 39 / 17 / 1$ \\
Glasgow prognostic score (0/1/2) & $51 / 16 / 6$ \\
Prognostic nutritional index & $44.2[31.0-59.0]$ \\
NRC-mortality (\%) & $1.7[0.5-10.6]$ \\
pT (1a/1b/2/3/4a/4b) & $13 / 29 / 9 / 8 / 12 / 2$ \\
pN (0/1/2/3a) & $40 / 17 / 12 / 4$ \\
pStage (IA/IB/IIA/IIB/IIIA/III) & $32 / 15 / 5 / 3 / 12 / 6$ \\
Surgical procedure (total gastrectomy/distal & $28 / 45$ \\
gastrectomy) & \\
Surgical approach (open/laparoscopic) & $62 / 11$ \\
Lymphadenectomy (<D2/D2) & $49 / 24$ \\
Operative time (min) & $241[88-800]$ \\
Blood loss (ml) & $351[28-3257]$ \\
Post-operative complications ${ }^{\text {a }}$ (yes/no) & $22 / 51$ \\
Adjuvant chemotherapy ${ }^{\text {b }}$ (yes/no) & $8 / 15$ \\
\hline ECOG-PS Eastern Cooperative Oncology Group Performance Status, NRC- \\
mortality The operative mortality calculated by the National Clinical Database \\
Risk Calculator \\
a Clavien-Dindo grade 2 or more \\
b Patients with pStage II or III except for T1 \\
\end{tabular}

procedure were the independent prognostic factors for OS (Table 2). By contrast, ECOG-PS, NRC-mortality, and pStage were significantly correlated with DSS in the univariate analysis. In multivariate analysis, the independent prognostic factors for DSS were ECOG-PS and pStage and not NRC-mortality (Table 3 ).

\section{Discussion}

Surgical resection for elderly patients is accompanied with significant perioperative mortality and frequent postoperative complications $[4,5]$. In addition, the life expectancy of this population is limited, in comparison with that of young patients. Therefore, the indications of surgical treatment should be discussed comprehensively based on various patient- and tumor-related factors. In this study, 20 patients $(27 \%)$ died from diseases other than gastric cancer during the follow-up period of 5 years after gastrectomy. This was an indispensable result, and OS, including deaths from diseases other than gastric cancer, should be considered equally important as DSS in elderly patients. Surgical indications should be determined by considering not only DSS but also OS, especially for elderly patients. The results of the current study clearly showed that NRC mortality is useful for predicting OS but not DSS.

Previous reports have identified sex [18, 19]. ECOGPS [19], surgical procedure [4, 7], PNI [7, 20], and postoperative complications $[7,19]$, as predictors of OS

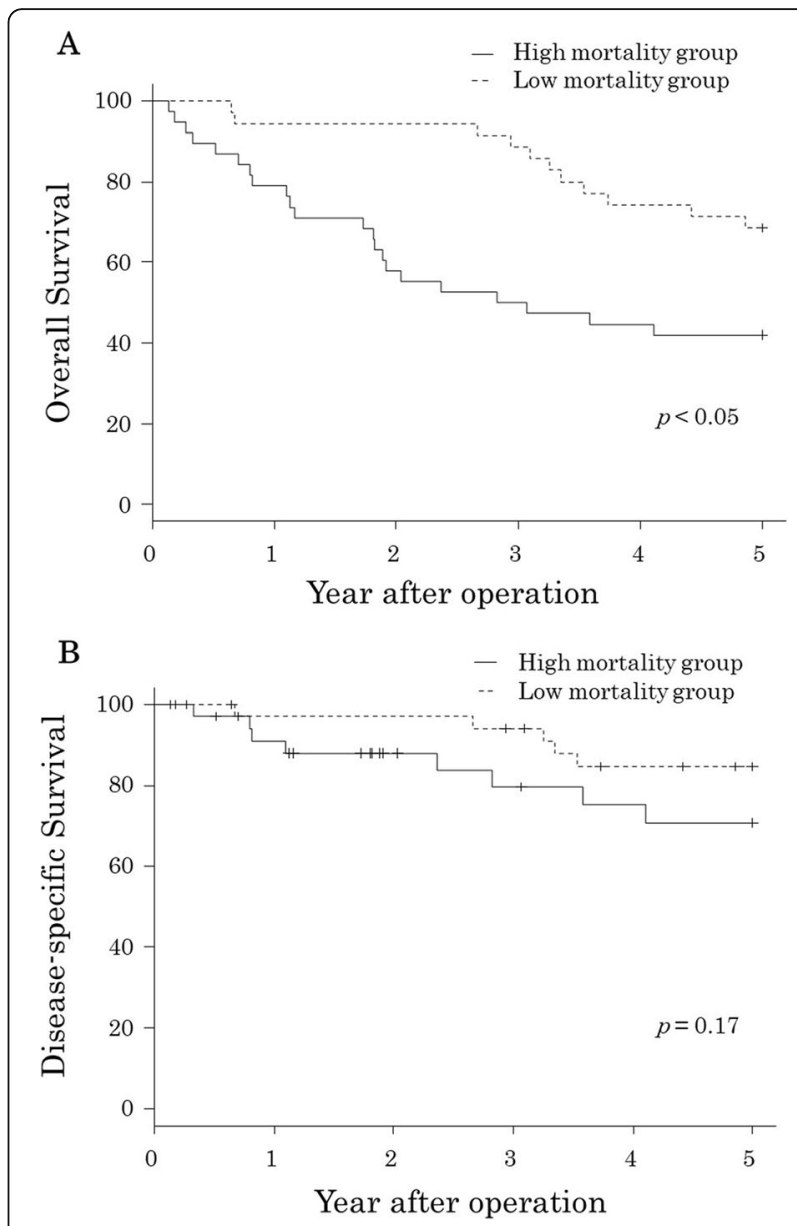

Fig. 2 Survival curves of the group of elderly patients with gastric cancer after gastrectomy, according to the operative mortality risk calculated by the National Clinical Database risk calculator. a Overall survival. b Disease-specific survival

among elderly patients with gastric cancer after gastrectomy. In our study, NRC-mortality, in addition to ECOG-PS and surgical procedure, was found to be the independent predictors of OS. When concerning surgical procedures, total gastrectomy may sometimes result in malnutrition [21] and aspiration pneumonia, particularly in elderly patients [22]. Given these insights, it may be better to avoid total gastrectomy for elderly patients with gastric cancer. On the other hand, postoperative complications have been recognized as reliable prognostic factors after curative resection of various cancers, including gastric cancer [7, 17, 23-25]. Based on our recent analysis that demonstrated a possible correlation between the adverse prognostic effect and immune status of patients [26], the immunocompromised state of elderly patients might have affected our current findings.

The NCD Risk Calculator was originally a tool for the prediction surgical morbidity and short-term surgical mortality [10]. The NRC-mortality was calculated based 
Table 2 Survival analysis of variables predicting prognostic factors for overall survival in elderly patients with gastric cancer after gastrectomy

\begin{tabular}{|c|c|c|c|c|c|c|}
\hline \multirow[b]{2}{*}{ Variable } & \multicolumn{3}{|c|}{ Univariate } & \multicolumn{3}{|c|}{ Multivariate } \\
\hline & $\overline{\mathrm{HR}}$ & $95 \% \mathrm{Cl}$ & $p$ value & $\overline{\mathrm{HR}}$ & $95 \% \mathrm{Cl}$ & $p$ value \\
\hline Sex (male) & 1.613 & $0.768-3.391$ & 0.207 & & & \\
\hline ECOG PS $(\geqq 2)$ & 4.727 & $2.356-9.485$ & $<0.001$ & 2.564 & $0.163-0.932$ & 0.034 \\
\hline Glasgow prognostic score $(\geqq 1)$ & 1.599 & $0.786-3.255$ & 0.195 & & & \\
\hline Prognostic nutritional index & 0.938 & $0.888-0.991$ & 0.023 & 0.980 & $0.919-1.045$ & 0.541 \\
\hline NRC-mortality & 1.336 & $1.195-1.494$ & $<0.001$ & 1.213 & $1.053-1.396$ & 0.007 \\
\hline pStage $(\geqq I)$ & 1.976 & $0.994-3.926$ & 0.052 & & & \\
\hline Surgical procedure (total gastrectomy) & 2.509 & $1.259-4.997$ & 0.009 & 2.285 & $1.115-4.682$ & 0.024 \\
\hline Lymphadenectomy (<D2) & 1.414 & $0.657-3.043$ & 0.376 & & & \\
\hline Operative time & 1 & $0.996-1.003$ & 0.734 & & & \\
\hline Blood loss & 1 & $0.999-1.001$ & 0.997 & & & \\
\hline Postoperative complications ${ }^{\mathrm{a}}$ (yes) & 2.034 & $1.010-4.093$ & 0.047 & 1.396 & $0.653-2.983$ & 0.390 \\
\hline Adjuvant chemotherapy (yes) & 0.476 & $0.641-6.890$ & 0.220 & & & \\
\hline
\end{tabular}

ECOG PS Eastern Cooperative Oncology Group Performance Status, NRC-mortality The operative mortality calculated by the National Clinical Database Risk Calculator, $H R$ hazard ratio

${ }^{a}$ Clavien-Dindo grade 2 or more

on logistic analysis from a large-scale NCD database, in which surgery-related deaths were registered from various causes, including deaths secondary to complications, worsening of comorbidities, and sudden deaths of unknown cause. In this study, we found that the NRCmortality predicted not only the short-term mortality rate but also the long-term outcomes of elderly patients with gastric cancer after gastrectomy. In this population, the perioperative mortality risk might correlate with the risks of death secondary to worsening of comorbidities and of sudden deaths in both the perioperative and late phases after gastrectomy and, consequently, might be related with OS, as shown by our analysis. Furthermore, no elderly patients with NRC-mortality $>4.1$ survived for 5 years postoperatively, which may indicate that the higher the NRC-mortality, the lower the expected survival.

POSSUM (Physiological and Operative Severity Score for the enUmeration of Mortality and morbidity) [27] and E-PASS (Estimation of Physiologic Ability and

Table 3 Survival analysis of variables predicting prognostic factors for disease-specific survival in elderly patients with gastric cancer after gastrectomy

\begin{tabular}{|c|c|c|c|c|c|c|}
\hline \multirow[b]{2}{*}{ Variable } & \multicolumn{3}{|c|}{ Univariate } & \multicolumn{3}{|c|}{ Multivariate } \\
\hline & $\mathrm{HR}$ & $95 \% \mathrm{Cl}$ & $p$ value & HR & $95 \% \mathrm{Cl}$ & $p$ value \\
\hline Sex (male) & 0.831 & $0.279-2.473$ & 0.739 & & & \\
\hline ECOG PS $(\geqq 2)$ & 3.73 & $1.203-11.57$ & 0.023 & 7.978 & $1.633-38.97$ & 0.01 \\
\hline Glasgow prognostic score $(\geqq 1)$ & 2.428 & $0.815-7.24$ & 0.111 & & & \\
\hline Prognostic nutritional index & 0.927 & $0.850-1.012$ & 0.089 & & & \\
\hline NRC-mortality & 1.272 & $1.039-1.558$ & 0.020 & 1.038 & $0.794-1.357$ & 0.785 \\
\hline pStage $(\geqq I)$ & 5.464 & $1.679-17.78$ & 0.005 & 9.375 & $2.202-39.92$ & 0.002 \\
\hline Surgical procedure (total gastrectomy) & 1.865 & $0.623-5.583$ & 0.265 & & & \\
\hline Lymphadenectomy (< D2) & 0.623 & $0.209-1.854$ & 0.395 & & & \\
\hline Operative time & 1 & $0.991-1.003$ & 0.324 & & & \\
\hline Blood loss & 1 & $0.998-1.001$ & 0.696 & & & \\
\hline Postoperative complications ${ }^{a}$ (yes) & 2.744 & $0.921-8.178$ & 0.070 & & & \\
\hline Adjuvant chemotherapy (yes) & 0.386 & $0.337-19.94$ & 0.360 & & & \\
\hline
\end{tabular}

ECOG PS Eastern Cooperative Oncology Group Performance Status, NRC-mortality The operative mortality calculated by the National Clinical Database Risk Calculator, $H R$ hazard ratio

${ }^{\text {a }}$ Clavien-Dindo grade 2 or more 
Surgical Stress) [28] are well-known prognostic scoring systems that are based on statistical analysis of actual surgical data. However, both scoring systems provide a comprehensive prognostic assessment only after surgery and may not be suitable for accurately predicting the surgical risk prior to surgery. Moreover, the E-PASS scoring system shows that postoperative complications mainly depend on the surgical stress score, which is the actual surgical invasive outcome score [28]. Given this, the NRC-mortality rate, compared with POSSUM and E-PASS, may be more ideal tool for perioperative risk assessment of the short- and long-term outcomes. Risk assessment based on the POSSUM scoring system is known to deviate from the actual results of a limited population, such as low-risk cases and elderly patients $[29,30]$. Moreover, assessments using these scoring systems have been reported to not reflect the prognosis of elderly patients [18].

There were some limitations in this study. First, it was small-scale and was done at a single institution. Further multi-institutional analyses of large number of patients should be conducted to confirm the current results. Second, the cohort included only a small number of patients who underwent laparoscopic gastrectomy, which is less invasive and may affect the long-term outcome in elderly patients. Concerning laparoscopic and robotic procedures for the elderly, huge numbers of patients' clinicopathological information would be collected in the NCD system, which shall elucidate the clinical utility of the NRC-mortality in minimally invasive surgeries in the future.

In conclusion, the NRC-mortality, as well as ECOG-PS and surgical procedure, might be clinical useful for predicting not only surgical mortality but also OS after gastrectomy in elderly patients with gastric cancer. As much as possible, gastrointestinal surgeons should avoid performing total gastrectomy on elderly patients with gastric cancer and consider treatment without gastrectomy, particularly in cases with poor PS. The NCD Risk Calculator may help in the proper surgical risk assessment of such patients.

\section{Abbreviations}

NCD: National Clinical Database; NRC-mortality: Operative mortality calculated by the National Clinical Database Risk Calculator; ECOGPS: Performance status of the Eastern Cooperative Oncology Group; GPS: Glasgow prognostic score; PNI: Onodera's prognostic nutritional index; pStage: Pathologic stage of gastric cancer; OS: Overall survival; DSS: Diseasespecific survival

\section{Acknowledgements}

We have no acknowledgments.

\section{Authors' contributions}

Hidenori Akaike conducted majority of the experiments and wrote the manuscript. Yoshihiko Kawaguchi and Daisuke Ichikawa designed the research and helped draft the manuscript. All the other authors contributed to data collection and interpretation and reviewed the manuscript critically The author(s) read and approved the final manuscript.

\section{Funding}

There was no funding in writing this manuscript.

\section{Availability of data and materials}

This was not applicable to this manuscript.

\section{Ethics approval and consent to participate}

All procedures were in accordance with the ethical standards of the responsible institutional and national committees on human experimentation and with the Helsinki Declaration of 1964 and its later versions. Informed consent or its substitute for study inclusion was obtained from all patients.

This article does not contain any studies by any of authors on human or animal subjects.

\section{Consent for publication}

This was not applicable to this manuscript, which does not contain personal data.

\section{Competing interests}

All authors have no potential conflicts of interest, including relevant financial interests, activities, relationships, and affiliations.

Received: 13 August 2020 Accepted: 15 October 2020

Published online: 30 October 2020

\section{References}

1. United Nation. Population Division. World Population Prospects (2019). https://population.un.org/wpp/. Accessed 14 Apr 2020.

2. National Cancer Center, Japan. Cancer Information Service, National estimates of cancer incidence based on cancer registries in Japan (19752013). https://ganjoho.jp/en/professional/statistics/table_download.html. Accessed 03 Apr 2020.

3. Songun I, Putter $H$, Kranenbarg MKE, et al. Surgical treatment of gastric cancer: 15-year follow-up results of the randomized nationwide Dutch D1D2 trial. Lancet Oncol. 2010;11:439-49.

4. Katai H, Sasako M, Sano T, et al. The outcome of surgical treatment for gastric carcinoma in the elderly. Jpn J Clin Oncol. 1998;28:112-5.

5. Takeuchi $D$, Koide N, Suzuki A, et al. Postoperative complication in elderly patients with gastric cancer. J Surg Res. 2015;198:317-26.

6. Nelen SD, Verhoeven RHA, Lemmems VEPP, et al. Increasing survival gap between young and elderly gastric cancer patients. Gastric Cancer. 2017;20: 919-28.

7. Ueno D, Matsumoto $H$, Kubota $H$, et al. Prognostic factors for gastrectomy in elderly patients with gastric cancer. World J Surg Oncol. 2017. https://doi. org/10.1186/s12957-017-1131-6.

8. Khuri SF, Daley J, Henderson W, et al. The department of veterans affairs' NSQIP: The first national, validated, outcome-based, risk-adjusted, and peercontrolled program for the measurement and enhancement of the quality of surgical care. National VA surgical quality improvement program. Ann Surg. 1998:228:491-507.

9. Hall BL, Hamilton BH, Richards $\mathrm{K}$, et al. Does surgical quality improve in the American college of surgeons' national surgical quality improvement program: An evaluation of all participating hospitals. Ann Surg. 2009;250: 363-76.

10. Gotoh M, Miyata $H$, Hashimoto $H$, et al. National Clinical Database feedback implementation for quality improvement of cancer treatment in Japan: from good to great through transparency. Surg Today. 2016;46:38-47.

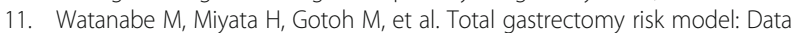
from 20,011 Japanese patients in a nationwide internet-based database. Ann Surg. 2014;260:1034-9.

12. Kikuchi $\mathrm{H}$, Miyata $\mathrm{H}$, Konno $\mathrm{H}$, et al. Development and external validation of preoperative risk models for operative morbidities after total gastrectomy using a Japanese web-based nationwide registry. Gastric Cancer. 2017;20: 987-97.

13. Kurita N, Miyata $H$, Gotoh M, et al. Risk model for distal gastrectomy when treating gastric cancer on the basis of data from 33,917 Japanese patients 
collected using a nationwide web-based data entry system. Ann Surg. 2015; 262:295-303.

14. Kunisaki $\mathrm{C}$, Miyata $\mathrm{H}$, Konno $\mathrm{H}$, et al. Modeling preoperative risk factors for potentially lethal morbidities using a nationwide Japanese web-based database of patients undergoing distal gastrectomy for gastric cancer. Gastric Cancer. 2017;20:496-507.

15. Onodera T, Goseki N, Kosaki G. Prognostic Nutritional index in gastrointestinal surgery of malnourished cancer patients. Nihon Geka Gakkai Zasshi. 1984;85:1001-5.

16. Brierley JD, Gospodarowica MK, Wittekind C. TNM classification of malignant tumors. 8th ed. Chichester: Wiley Blackwell; 2017.

17. Japanese Gastric Cancer Association. Japanese gastric cancer treatment guidelines 2014 (ver.4). Gastric Cancer. 2017;20:1-19.

18. Endo S, Yoshikawa $\mathrm{Y}$, Hatanaka $\mathrm{N}$, et al. Prognostic factor for gastrectomy in elderly patients. Int Surg. 2014;99:166-73.

19. Hikage M, Tokunaga M, Makuuchi R, et al. Surgical outcomes after gastrectomy in very elderly patients with gastric cancer. Surg Today. 2018; 48:773-82.

20. Watanabe $\mathrm{M}$, Iwatsuki $\mathrm{M}$, Iwagami S, et al. Prognostic nutritional index predicts outcomes of gastrectomy in the elderly. World I Surg. 2012;36: 1632-9.

21. Fujiya K, Kawamura T, Omae K, et al. Impact of malnutrition after gastrectomy for gastric cancer on long-term survival. Ann Surg Oncol. 2018; 25:974-83.

22. Shibata C, Ogawa H, Nakano T, et al. Influence of age on postoperative complication especially pneumonia after gastrectomy for gastric cancer BMC Surg. 2019. https://doi.org/10.1186/s12893-019-0573-x.

23. Kataoka K, Takeuchi H, Mizusawa J, et al. Prognostic impact of postoperative morbidity after esophagectomy for esophageal cancer: Exploratory analysis of JCOG9907. Ann Surg. 2017;265:1152-7.

24. Artinyan A, Orcutt ST, Anaya DA, et al. Infectious postoperative complications decrease long-term survival in patients undergoing curative surgery for colorectal cancer: A study of 12,075 patients. Ann Surg. 2015; 261:497-505.

25. Aoyama T, Murakawa M, Katayama Y, et al. Impact of postoperative complications on survival and recurrence in pancreatic cancer. Anticancer Res. 2015;35:2401-9.

26. Maruyama S, Kawaguchi Y, Akaike $H$, et al. Postoperative complications have minimal impact on long-term prognosis in immunodeficient patients with esophageal cancer. Ann Surg Oncol. 2020. https://doi.org/10.1245/s10434020-08245-8.

27. Copeland GP, Jones D, Walters M. POSSUM: a scoring system for surgical audit. Br J Surg. 1991;78:355-60.

28. Haga $Y$, Ikei $S$, Ogawa M. Estimation of physiologic ability and surgical stress (E-PASS) as a new prediction scoring system for postoperative morbidity and mortality following elective gastrointestinal surgery. Surg Today. 1999; 29:219-25.

29. Whiteley MS, Prytherch DR, Higgins B, et al. An evaluation of the POSSUM surgical scoring system. Br J Surg. 1996;83:812-5.

30. Slim K, Panis Y, Alves A, et al. Predicting postoperative mortality in patients undergoing colorectal surgery. World J Surg. 2006;30:100-6.

\section{Publisher's Note}

Springer Nature remains neutral with regard to jurisdictional claims in published maps and institutional affiliations.

Ready to submit your research? Choose BMC and benefit from:

- fast, convenient online submission

- thorough peer review by experienced researchers in your field

- rapid publication on acceptance

- support for research data, including large and complex data types

- gold Open Access which fosters wider collaboration and increased citations

- maximum visibility for your research: over $100 \mathrm{M}$ website views per year

At $\mathrm{BMC}$, research is always in progress.

Learn more biomedcentral.com/submissions 